\title{
DTNQ-Pro, a Mimetic Dipeptide, Sensitizes Human Colon Cancer Cells to 5-Fluorouracil Treatment
}

\author{
Isabel Gomez-Monterrey, ${ }^{1}$ Pietro Campiglia, ${ }^{2}$ Ilaria Scognamiglio, ${ }^{3}$ \\ Daniela Vanacore, ${ }^{3}$ Alessandra Dicitore, ${ }^{4}$ Angela Lombardi, ${ }^{3}$ Michele Caraglia, ${ }^{3}$ \\ Ettore Novellino, ${ }^{1}$ and Paola Stiuso ${ }^{3}$ \\ ${ }^{1}$ Department of Pharmaceutical and Toxicological Chemistry, University of Naples Federico II, Naples, Italy \\ ${ }^{2}$ Department of Pharmaceutical Sciences, University of Salerno, Fisciano, Salerno, Italy \\ ${ }^{3}$ Department of Biochemistry, Biophysics and General Pathology, Second University of Naples, Naples, Italy \\ ${ }^{4}$ Italian Institute for Auxology, IRCC, 20145 Milan, Italy
}

Correspondence should be addressed to Paola Stiuso; paola.stiuso@unina2.it

Received 1 February 2013; Accepted 27 March 2013

Academic Editor: Giuseppe De Rosa

Copyright (c) 2013 Isabel Gomez-Monterrey et al. This is an open access article distributed under the Creative Commons Attribution License, which permits unrestricted use, distribution, and reproduction in any medium, provided the original work is properly cited.

\begin{abstract}
The resistance of growing human colon cancer cells to chemotherapy agents has been correlated to endogenous overexpression of stress proteins including the family of heat shock proteins (HSPs). Previously, we have demonstrated that a quinone-based mimetic dipeptide, named DTNQ-Pro, induced differentiation of growing Caco-2 cells through inhibition of HSP70 and HSP90. In addition, our product induced a HSP27 and vimentin intracellular redistribution. In the present study, we have evaluated whether a decrease of stress proteins induced by DTNQ-Pro in Caco-2 cells could sensitize these cells to treatment with 5-fluorouracil (5FU) cytotoxicity. The pretreatment of Caco-2 with $500 \mathrm{nM}$ of DTNQ-Pro increases lipid peroxidation and decreases expression of p38 mitogen-activated protein kinase (MAPK) and FOXO3a. At the same experimental conditions, an increase of the 5-FUinduced growth inhibition of Caco-2 cells was recorded. These effects could be due to enhanced DTNQ-Pro-induced membrane lipid peroxidation that, in turn, causes the sensitization of cancer cells to the cytotoxicity mediated by 5-FU.
\end{abstract}

\section{Introduction}

Adenocarcinoma cells, such as colorectal cancer (CRC) cells, are remarkably resistant to radiation or chemotherapyinduced damage. As a consequence, the tumours are hard to treat and often proliferate rapidly, even under conditions that may adversely affect normal cells. For several years, 5fluorouracil (5-FU), a pyrimidine antimetabolite, has been the drug of choice for the treatment of CRC as well as head and neck, pancreatic, and breast carcinomas. 5-FU is known to block DNA synthesis by the inhibition of thymidylate synthase (TS), which is regulated by cell cycle proteins controlled by phosphorylation [1]. Unfortunately, many of the schedules based upon 5-FU alone or in combination with other agents become ineffective during the course of the treatment due to the occurrence of drug resistance to 5-FU. Between several survival pathways activated in cancer cells to antagonize the antiproliferative activities of antineoplastic agents [2-4]. The mechanisms underlying the survival advantage can also be partially related to the increased expression of stress proteins $[5,6]$. In fact, in contrast to normal cells, the basal levels of inducible heat shock proteins (HSPs) are frequently higher in tumour cells $[7,8]$. The high expression of members of the HSP family in CRC cells has been associated with both metastases and resistance to chemotherapy. Moreover, in experimental models, HSP27 and HSP70 have been shown to increase tumorigenicity of cancer cells, and HSP depletion can induce a spontaneous regression of the tumour [911]. Recent data provide direct evidence on the association between HSP27 protein expression levels and 5-FU sensitivity in Caco- 2 cells. In fact, the suppression of HSP27 expression in these cells may promote 5-FU sensitivity by inducing apoptosis, despite the acceleration in 5-FU metabolism [12]. 
HSP27 has been also implicated in a wide range of cell functions including cell protection, differentiation, and cell proliferation [13-15]. Moreover, HSPs are often associated with specific lipids or particular membrane areas (such as lipid rafts). In this light, changes of membrane physical state alter HSP gene expression [16-18]. The correlation between HSPs and control of cell proliferation is demonstrated by the fact that they are targets of important cell growth regulators such as mitogen-activated protein kinases (MAPKs) [19]. Moreover, the latter can be modulated by HSP multichaperone complex that protects MAPKs from proteasome-mediated degradation [20]. In addition, it has been reported that the inhibition of the multichaperone complex can sensitize cancer cells to agents raised against ERK-mediated pathways [21].

In mammalian cells, there are three well-characterized subfamilies of MAPKs: the extracellular signal-regulated kinases (ERK), the c-Jun N-terminal kinases (JNK, also known as the stress-activated protein kinases), and the p38 MAPK kinases. Each MAPK is activated through a specific phosphorylation cascade. ERK pathway is activated in response to growth factors, conferring a survival advantage on cells [22]. In contrast, JNK and p38 MAPK are activated in response to a variety of environmental stressors and inflammatory cytokines, which are frequently associated with the induction of apoptosis $[23,24]$. Moreover, it was demonstrated that the p38 MAPK-Hsp27 axis plays an essential role in cancer stem cells-mediated Cis-platinum resistance in oral cancer [25]. Therefore, the development of specific modulators of HSP expression could be desirable either to shed further light on the functional roles of these important proteins in cell survival and in cell death or to further develop new clinically useful antitumour drugs.

In our previous report [26], we have demonstrated that DTNQ-Pro, a quinone-based pentacyclic derivative, modulated cellular redox status inducing cell cycle arrest and differentiation and, finally, driving cells to programmed cell death. Moreover, after $48 \mathrm{~h}$ of DTNQ-Pro treatment a decrease of mitochondrial superoxide anion induced by manganese superoxide dismutase (MnSOD) was recorded in Caco-2 cells. This effect was followed by a subsequent decrease of HSP70 expression and an increased membrane lipid peroxidation. The oxidative damage of the membrane induced a redistribution of both HSP27 and vimentin and forced Caco- 2 cells to differentiate into enterocytes. On the other hand, the second treatment with DTNQ-Pro activated the apoptotic pathway. The ability of DTNQ-Pro to shift the undifferentiated Caco-2 cells to differentiated enterocytes and then undergo a process of programmed cell death strongly suggests that this compound should be additionally investigated for its potential use in new combination chemotherapy for colon cancer. The goal of the present study was to determine if the pretreatment with DTNQPro can modulate the cytotoxic response of $\mathrm{Caco} 2$ cells to fluorouracil (5-FU) and assess the potential mechanisms underlying such modulation. In this report, we showed that increased Caco-2 cell differentiation by pretreatment with DTNQ-Pro enhanced the cytotoxic response of human colon carcinoma cells to 5-FU by modulating the expression of molecules that are associated with either drug sensitivity or resistance.

\section{Material and Methods}

2.1. Cell Cultures. Human colon adenocarcinoma Caco-2 cells (American Type Culture Collection, Rockville, MD, USA) were grown at $37^{\circ} \mathrm{C}$ in h-glucose MEM containing: $1 \%$ (by vol) nonessential amino acids and supplemented with $10 \%$ (by vol) decomplemented fetal bovine serum (FBS) (Flow, McLean, VA, USA), $100 \mathrm{U} \cdot \mathrm{mL}^{-1}$ penicillin, $100 \mathrm{mg} \cdot \mathrm{mL}^{-1}$ streptomycin, $1 \% \mathrm{~L}$-glutamine, and $1 \%$ sodium pyruvate. Cells were grown in six multiwell plates (17-21 passages) in a humidified atmosphere of $95 \%$ air $/ 5 \% \mathrm{CO}_{2}$ at $37^{\circ} \mathrm{C}$. After incubation for $4 \mathrm{~h}$ in Dulbecco's modified Eagle's medium (DMEM) with 10\% FBS, the cells were washed with $1 \%$ phosphate-buffered saline (PBS) to remove unattached dead cells and were incubated with $500 \mathrm{nM}$ concentration of DTNQ-Pro for $48 \mathrm{~h}$ (D-Caco-2). All experiments were performed in triplicate.

2.2. Evaluation of Growth Inhibition of D-Caco-2 Cells. We assessed the sensitivity of the to 5-FU using a microplate colorimetric assay that measures the ability of viable cells to transform a soluble tetrazolium salt (MTT) [27] to an insoluble purple formazan precipitate. D-Caco-2 cells were plated at the appropriate density in 96-well microtitre plates. After $4 \mathrm{~h}$, cells were exposed to different concentration ( 0 $200 \mu \mathrm{M})$ of 5 -FU for $48 \mathrm{~h} .50 \mathrm{~mL}$ of MTT $\left(1 \mathrm{mg} \cdot \mathrm{mL}^{-1}\right)$ and $200 \mathrm{~mL}$ of medium were added to the cells in each well. After a $4 \mathrm{~h}$ incubation at $37^{\circ} \mathrm{C}$, the medium was removed; then the formazan crystals were solubilized by adding $150 \mathrm{~mL}$ of DMSO and by mixing it in an orbital shaker for $5 \mathrm{~min}$. Absorbance at $550 \mathrm{~nm}$ was measured using a plate reader. Experiments were performed in triplicate. The percent inhibition of the treated cells was calculated by the following formula:

$$
\% \text { Inhibition }=\frac{\mathrm{A}_{550} \text { treated }}{\mathrm{A}_{550} \mathrm{CTR}} .
$$

2.2.1. Alkaline Phosphatase (ALP) Activity Evaluation. ALP activity was used as marker of the degree of differentiation of D-Caco-2 cells. Attached and floating cells were washed and lysed with $0.25 \%$ sodium deoxycholate, essentially as described by Herz et al. [28]. ALP activity was determined using Sigma Diagnostics ALP reagent (no. 245). Total cellular protein content of the samples was determined in a microassay procedure as described by Bradford [29] using the Coomassie protein assay reagent kit (Pierce). ALP activity was calculated as units of activity per milligram of protein.

2.3. Lipid Peroxidation Assay. Lipid peroxidation was evaluated using an analytical quantitative methodology. It relies upon the formation of a coloured adduct produced by the stechiometric reaction of aldehydes with thiobarbituric acid (TBA). The thiobarbituric acid reactive substances (TBARS) assay was performed on membranes extracted from cells, 
using an icecold lysis buffer $(50 \mathrm{mM}$ Tris, $150 \mathrm{mM} \mathrm{NaCl}$, $10 \mathrm{mM}$ EDTA, 1\% Triton) supplemented with a mixture of protease inhibitors. The homogenate was centrifuged at $1200 \mathrm{~g}$ for $10 \mathrm{~min}$ in order to separate cytosol (supernatants) from membranes (pellet). The pellet was dissolved in $50 \mathrm{mM}$ Tris, $150 \mathrm{mM} \mathrm{NaCl}$, and $10 \mathrm{mM}$ EDTA, and the protein content of the samples was determined by Bio-Rad assay (BioRad Laboratories, San Diego, CA, USA). Aliquots $(10 \mathrm{~mL})$ of the membrane preparation were added to $2 \mathrm{~mL}$ of TBAtrichloroacetic acid (TCA) (15\% TCA, $0.3 \%$ TBA in $0.12 \mathrm{~N}$ $\mathrm{HCl}$ ) solution at $100^{\circ} \mathrm{C}$ for $30 \mathrm{~min}$. The reaction was stopped by cooling the sample in cold water, and, after a centrifugation at $15000 \mathrm{~g}$ for $10 \mathrm{~min}$, the chromogen (TBARS) was quantified by spectrophotometry at a wavelength of $532 \mathrm{~nm}$. The amount of TBARS was expressed as $\mathrm{mM} \cdot \mathrm{mg}^{-1}$ proteins. All data are the mean \pm SD of three experiments.

2.4. Western Blot Assay. The effects of DTNQ-Pro on expression of HSP90, p38, p38, and FOXO3a were determined by Western blots. The cells lysates were prepared using an ice-cold lysis buffer $(50 \mathrm{mM}$ Tris, $150 \mathrm{mM} \mathrm{NaCl}, 10 \mathrm{mM}$ EDTA, 1\% Triton) supplemented with a mixture of protease inhibitors containing antipain, bestatin, chymostatin, leupeptin, pepstatin, phosphoramidon, pefabloc, EDTA, and aprotinin (Boehringer, Mannheim, Germany). Equivalent protein samples were resolved on $8 \%-12 \%$ sodium dodecyl sulphate-polyacrylamide gels and transferred to nitrocellulose membranes (Bio-Rad, Germany). For immunodetection, membranes were incubated overnight with specific antibodies at the concentrations recommended by the manufacturer. All antibodies were diluted in Tris buffered saline/Tween $20-1 \%$ milk powder. This step was followed by incubation with the corresponding horseradish peroxidase conjugated antibody (anti-mouse IgG 1:2000, anti-rabbit IgG 1:6000, Biosource, Germany). Bands were analysed by enhanced chemiluminescence (ECL kit, Amersham, Germany).

\section{Results}

3.1. Cytotoxic Effects Induced by 5-FU on Growing D-Caco2 Cells. Previously, we have shown the biochemical events elicited by DTNQ-Pro, a mimetic peptide, in growing human colon adenocarcinoma cells. Undifferentiated Caco-2 treated for $48 \mathrm{~h}$ with $500 \mathrm{nM}$ DTNQ-Pro presented an increased membrane lipid peroxidation and a redistribution of both HSP27 and vimentin [26]. Moreover, growing Caco-2 cells differentiate into enterocytes. Here the effect of conventional cytotoxic agent 5-FU was studied on exponentially growing pretreated DTNQ-Pro Caco-2 cell lines (D-Caco-2). Cells were treated for $48 \mathrm{~h}$ with $500 \mathrm{nM}$ DTNQ-Pro and, thereafter, different concentrations of 5-FU $(0-200 \mu \mathrm{M})$ were added to the cells for $48 \mathrm{~h}$. In exponentially growing cells, pretreatment with DTNQ-Pro potentiated the cell growth inhibition observed with 5-FU alone (Figure 1). As shown in Table 1, for growing Caco-2 cells, the concentration of 5-FU $(46 \mu \mathrm{M})$ that induced $50 \%$ of growth inhibition (IC:50) was reduced about 30 -fold in D-Caco-2 $(1.2 \mu \mathrm{M})$. All successive experiments were performed on Caco- 2 cell, treated for $48 \mathrm{~h}$ with $500 \mathrm{nM}$ DTNQ-Pro (D-Caco-2).

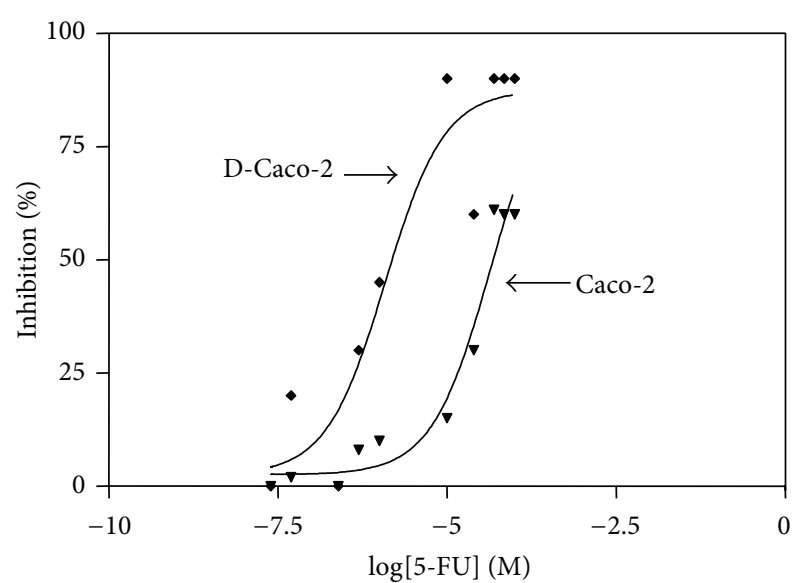

FIGURE 1: Sensitivity of the D-Caco-2 cells the to 5-FU. Both Caco2 and D-Caco-2 cells were plated in 96-well microtitre plates at the density of $3 \times 10^{3}$ cells/plate. After $4 \mathrm{~h}$, cells were exposed to different concentration $(0-200 \mu \mathrm{M})$ of 5 -FU for $48 \mathrm{~h}$. The percentage of inhibition was calculated with the formula reported in methods. Experiments were performed in triplicate.

TABLE 1: IC50 5-FU values (micromolar) in growing human colon carcinoma cell lines with or without DTNQ-Pro pretreatment. Values represent means $\pm \operatorname{SEM}(n=8), P<0.05$.

\begin{tabular}{lcc}
\hline & IC:50 on Caco-2 & IC:50 on D-Caco-2 \\
\hline $5-\mathrm{FU}$ & $46 \mu \mathrm{M}$ & $1.2 \mu \mathrm{M}$ \\
\hline
\end{tabular}

3.2. 5-FU Increases Cell Cycle Arrest and D-Caco-2 Differentiation. 5-FU is an antimetabolite known to specifically block cells in $\mathrm{S}$ phase. To elucidate whether 5-FU treatment of DCaco-2 determined cell cycle perturbation, we analysed the percentage cell cycle by FACS analysis. Cell cycle analysis of Caco-2 and D-Caco-2 cells revealed a percentage of cells of $54 \pm 4$ and $42 \pm 6 \%$ in G0/G1 phase, $35 \pm 5$ and $47 \pm 5 \%$ in $S$ phase, and $11 \pm 1 \%$ and $11 \pm 2 \%$ in G2/M phase, respectively (Figure 2). The additional treatment of the cells with $500 \mathrm{nM}$ 5-FU showed a significant $(P<0.014)$ accumulation of D-Caco-2 cells (56\%) in S phase if compared to Caco-2 (45\%) and a concomitant G0/G1 phase decrease (33\%) if compared to Caco-2 cells (44\%). As cell division arrest is one of the biological effects required for cell differentiation [30], we determined the effect of DTNQ-Pro on D-Caco-2 differentiation. In Figure 3(b) it is shown that ALP activity, as a marker of differentiation into enterocytes, correlated to postconfluent phase [31]. ALP activity was about 3-fold increased $(P<0.001)$ only in D-Caco- 2 cells treated with $500 \mathrm{nM} 5$-FU while it remained unaltered in the other cases.

\subsection{Lipid Peroxidation and Catalase Activity in D-Caco-2 Cells} after 5-FU Treatment. In Figure 3 we reported the values of both TBARS, as lipid peroxidation markers [32], and catalase activity, as scavenger enzyme, in both Caco-2 and D-Caco2 cells treated with $500 \mathrm{nM} 5$-FU. The incubation of Caco-2 cells with 5-FU determined a statistically significant decrease of TBARS values $(P<0.0015)$ with a concomitant increase of the catalase activity $(P<0.0124)$. In the D-Caco-2 the basal 


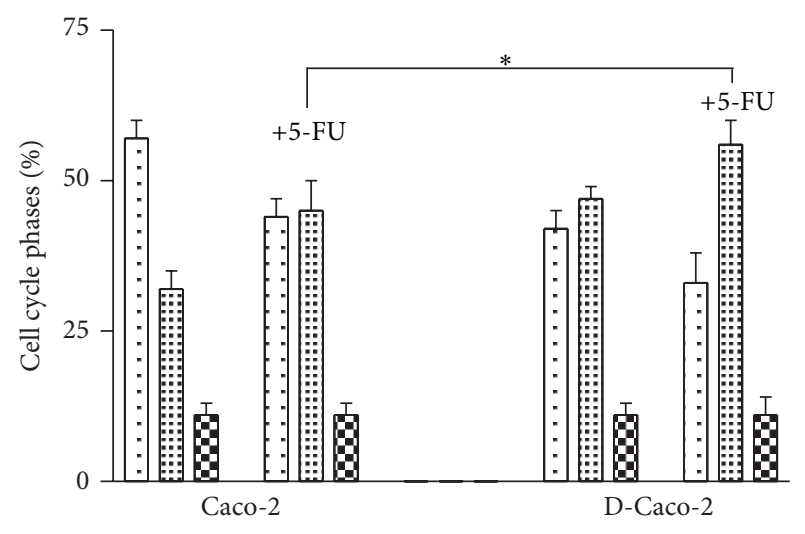

$\because \because \mathrm{G} 0 / \mathrm{G} 1$

\$ $\mathrm{G} 2 / \mathrm{M}$

(a)

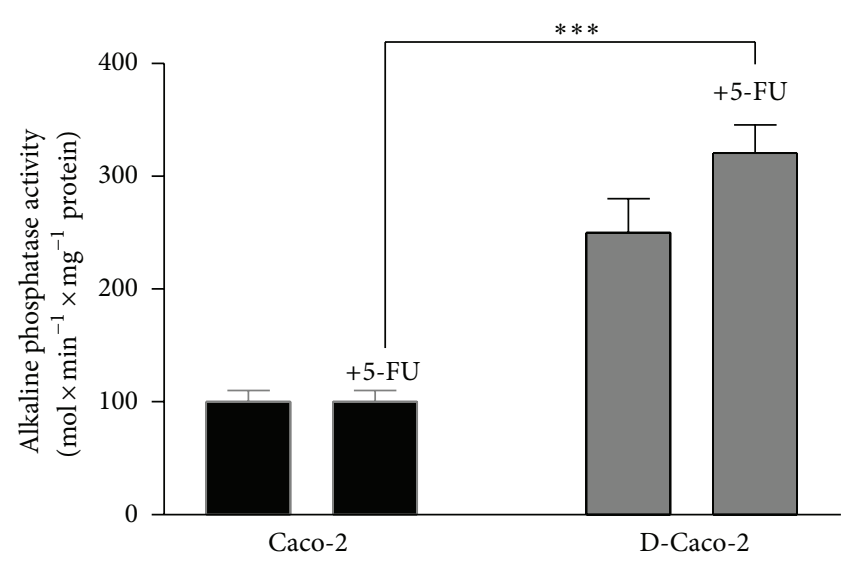

(b)

FIgUre 2: (a) Effects of 5-FU on the distribution of Caco-2 and DCaco-2 cells populations. Data represent the percentage of cells in each phase of the cell cycle. Cell cycle distribution was determined by DNA flow cytometric analysis. Samples from preconfluent Caco2 and D-Caco 2 cells was analysed after $48 \mathrm{~h}$ of treatment with $500 \mathrm{nM} 5$-FU. Numbers indicate percentage of cells in G0/G1, S and $\mathrm{G} 2 / \mathrm{M}$ phases. Data are representative of four separate analyses. (b) Differentiation effects of 5-FU of Caco-2 and D-Caco-2. The differentiation was assessed by measurement of ALP activity after $48 \mathrm{~h}$ of culture with $500 \mathrm{nM}$ of 5-FU. Summary data shown are means $\pm \operatorname{SEM}\left(n=4 ;{ }^{* * *} P<0.001\right)$.

levels of TBARS and catalase activity were 1.6 -fold and 0.5 fold higher, respectively, than those recorded in Caco-2 cells. No changes were observed in both TBARS values and catalase activity when the D-Caco- 2 cells were incubated with $500 \mathrm{nM}$ of 5-FU.

3.4. Evaluation of the Expression of Molecular Factors Involved in the Tumour Cell Resistance to 5-FU. We have evaluated, in D-Caco2 cells, the effects of 5-FU treatment on the expression of FOXO-3a, HSP90 and p38 MAPK proteins that are involved in mechanisms of cell resistance to 5-FU.

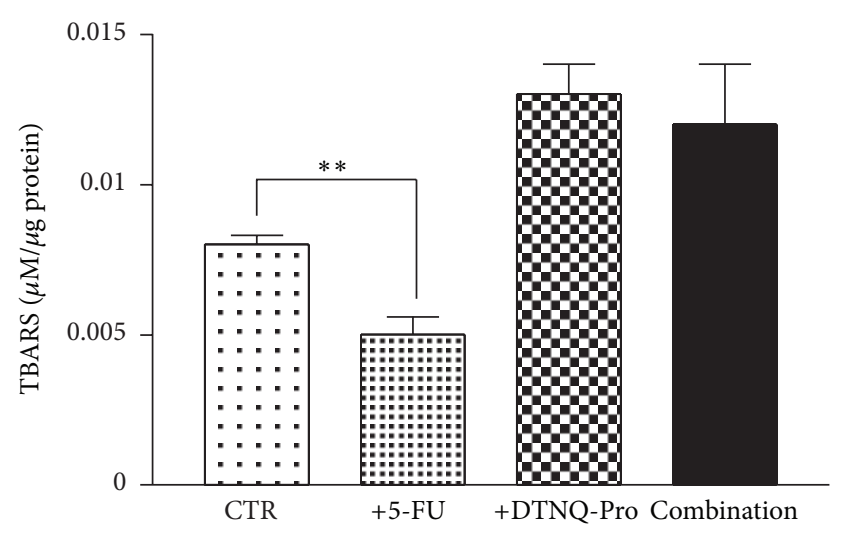

(a)

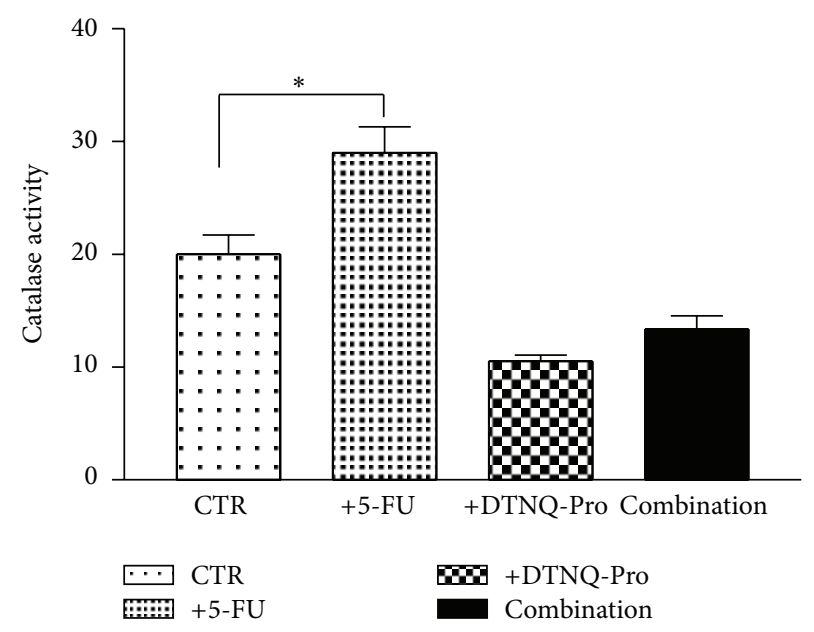

(b)

FIGURE 3: Effect of 5-FU D-Caco-2 treatment on TBARS. The cells were seeded in six multiwell plates at the density of $25 \times 10^{4}$ cells/plate and were incubated for the first $48 \mathrm{~h}$ with $500 \mathrm{nM}$ DTNQPro (D-Caco-2) the cells were washed to remove unattached dead cells and were incubated with and without $500 \mathrm{nM}$ of 5-FU for subsequently 48 h. (a) TBARS levels in Caco-2 (CTR) and D-Caco2 cells after $48 \mathrm{~h}$ of incubation without and with $500 \mathrm{nM} 5-\mathrm{FU}$; (b) catalase activity. Catalase activity in Caco-2 (CTR) and D-Caco-2 cells after $48 \mathrm{~h}$ of incubation without and with $500 \mathrm{nM} 5$-FU. The bars represent means \pm SEM of three independent experiments. Asterisks indicate significant difference between the D-Caco-2treated samples compared with control value ${ }^{* *} P<0.003$; ${ }^{*} P<$ 0.05 ; n.s.: not significant.

Western blot and densitometric analysis of HSP90, FOXO$3 \mathrm{a}$, and p38 MAPK in Caco2 after DTNQ-Pro treatment is shown in Figure 4. The Caco-2 cells expressed high levels of Hsp90, and this expression was 0.5 -fold lower in D-Caco2. Furthermore DTNQ-Pro Caco-2 treatment induced about 0.5 -fold decrease of both $\mathrm{p} 38$ and FOXO-3a expression. On the other hand, 5-FU induced about 3- and 2-fold increase of Hsp90 levels in Caco-2 and D-Caco-2 cells, respectively; moreover 5-FU weakly increased the expression of FOXO-3a and $\mathrm{p} 38$ in D-Caco-2 cells. 

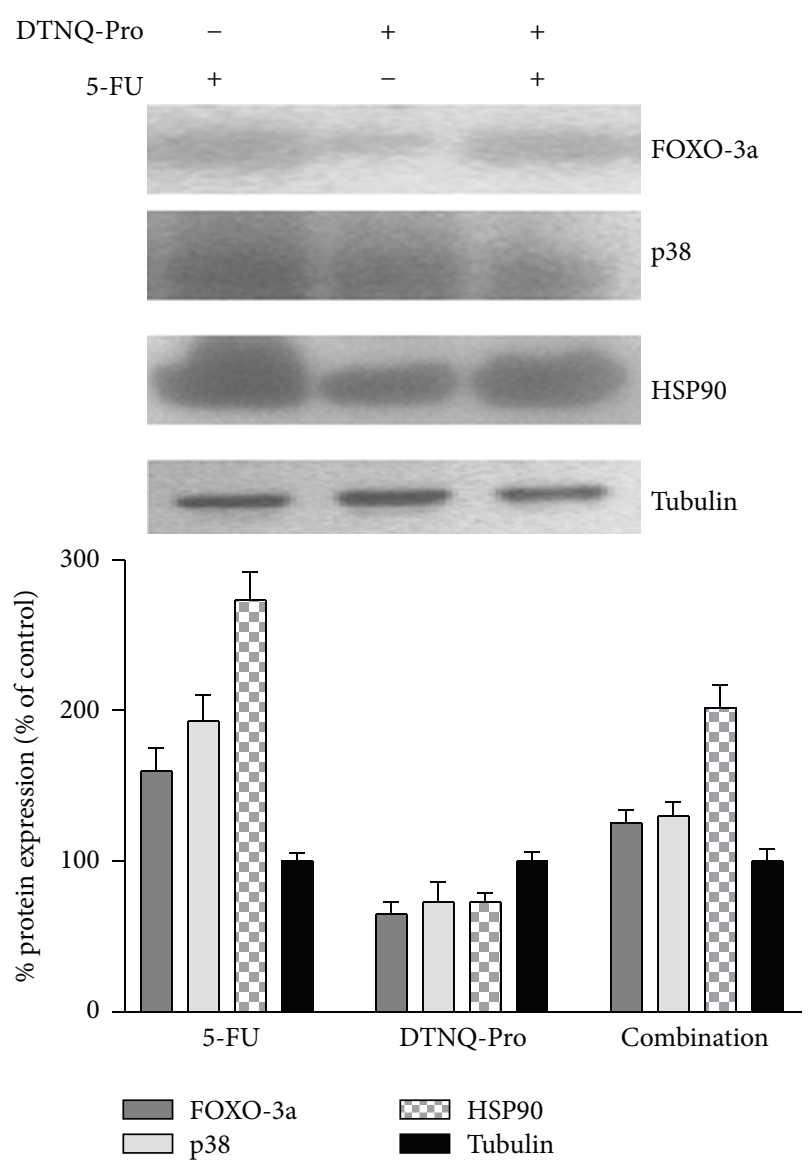

Figure 4: Expression of Foxo3a, p38, and HSP90 in Caco-2 and DCaco- 2 cells treated for $48 \mathrm{~h}$ with 5 -FU. The cells were incubated with $500 \mathrm{nM}$ of 5-FU, and the protein expression was evaluated by Western blotting. All the experiments were performed at least three times with similar results. The graphs show the summary data (as \% of expression in untreated cells), normalized to $\gamma$-tubulin expression after $48 \mathrm{~h}$ of treatment with 5 -FU. Data shown are means \pm SEM $\left(n=4 ;{ }^{*} P<0.05,{ }^{* *} P<0.003\right)$.

\section{Discussion}

Previously, we showed that DTNQ-Pro acts on two major targets involved in the resistance of CRC cells to chemotherapy agents: the process of cell differentiation and overexpression of HSP family proteins [26]. We have demonstrated that DTNQ-Pro induced cell membrane modifications by redistribution of HSP27 and vimentin within the cell. Moreover, DTNQ-Pro inhibited the growth by inducing $S$ phase cell cycle arrest and increased cellular differentiation.

In the present study, we show that DTNQ-Pro, a mimetic dipeptide, sensitizes human CRC cells to the conventional chemotherapy agent 5-FU. Exposure of Caco-2 cells to DTNQ-Pro induced a hydrogen peroxide $\left(\mathrm{H}_{2} \mathrm{O}_{2}\right)$ increase due to decreased catalase activity. At the same time, an increased rate of lipid peroxidation was recorded as evaluated by TBARS production. Lipid peroxidation occurred together with cell differentiation as demonstrated by the increased ALP activity. The treatment of D-Caco-2 cells with 5-FU caused an additional increase of both ALP activity and cell accumulation in S phase, while no increase of catalase activity or antagonism on TBARS values was recorded. Pretreatment of growing Caco-2 cell lines with $500 \mathrm{nM}$ of DTNQ-pro (D$\mathrm{Caco} 2$ ) induced also a decrease of FOXO3a protein expression with a consequent downregulation of D-cyclin (data not shown) and an accumulation of Caco-2 cells in the S-phase of the cell cycle. In fact, FOXO transcription factors [33] regulate the expression of antioxidants enzymes such as SOD and Catalase but, in addition to regulation of antioxidants, Foxo is also involved in the transcriptional upregulation of cell cycle inhibitors, including p21, p27, and p130, and downregulation of D-type cyclins. Therefore, our data demonstrate that $\mathrm{S}$ phase accumulation occurred together with regulation of transcriptional factors that are involved in the regulation of cell cycle.

5-FU is known to block DNA synthesis by the inhibition of thymidylate synthase (TS), which is regulated by cell cycle proteins controlled by phosphorylation [1]. Increased TS expression in tumors is an underlying mechanism by which tumor cells can escape from the toxic effect of 5-FU and become drug resistant [34]. In fact, the increased expression of the target is a generalized mechanism of resistance of tumour cells to antitumour agents determining an increase of the drug concentration needed to inhibit the molecular target.

DTNQ-Pro induces both cell accumulation in S phase and differentiation, with a probable decrease in the de novo DNA synthesis. On the basis of these considerations, we hypothesize that the level of TS expression could be reduced and this reduction may be directly responsible for the increase in sensitivity to 5-FU. Finally, we have found that DTNQ-Pro reduced HSP90 and p38 MAPK proteins. Hsp90 is a ubiquitous cellular protein and its function as a molecular chaperone is vital for cell survival [35] while p38 kinase is a final mediator of stress-induced pathways. We hypothesize that the increased responsiveness to 5-FU of DCaco- 2 could be attributed to (i) block of cell cycle in S phase and differentiation, (ii) decrease of HSP90 and p38 MAPK protein that can, in turn, promote the antiproliferative effects of 5-FU, and (iii) decreased expression of the 5-FU target. Our data provide evidence that DTNQ-pro is a promising chemotherapeutic agent that increases the chemosensitivity of growing adenocarcinoma colon cancer cells to 5-FU treatment.

\section{References}

[1] J. G. Kuhn, "Fluorouracil and the new oral fluorinated pyrimidines," Annals of Pharmacotherapy, vol. 35, no. 2, pp. 217-227, 2001.

[2] G. Vitale, C. H. J. van Eijck, P. M. van Koetsveld Ing et al., “Type I interferons in the treatment of pancreatic cancer: mechanisms of action and role of related Receptors," Annals of Surgery, vol. 246, no. 2, pp. 259-268, 2007.

[3] M. Marra, G. Salzano, C. Leonetti et al., "New self-assembly nanoparticles and stealth liposomes for the delivery of zoledronic acid: a comparative study," Biotechnology Advances, vol. 30, no. 1, pp. 302-309, 2011. 
[4] M. Caraglia, G. Vitale, M. Marra, A. Budillon, P. Tagliaferri, and A. Abbruzzese, "Alpha-interferon and its effects on signalling pathways within cells," Current Protein and Peptide Science, vol. 5, no. 6, pp. 475-485, 2004.

[5] M. Marra, A. Lombardi, E. Agostinelli et al., "Bovine serum amine oxidase and spm potentiate docetaxel and interferon- $\alpha$ effects in inducing apoptosis on human cancer cells through the generation of oxidative stress," Biochimica et Biophysica Acta, vol. 1783, no. 12, pp. 2269-2278, 2008.

[6] M. Caraglia, M. Marra, P. Tagliaferri et al., "Emerging strategies to strengthen the anti-tumour activity of type I interferons: overcoming survival pathways," Current Cancer Drug Targets, vol. 9, no. 5, pp. 690-704, 2009.

[7] C. Jolly and R. I. Morimoto, "Role of the heat shock response and molecular chaperones in oncogenesis and cell death," Journal of the National Cancer Institute, vol. 92, no. 19, pp. 1564$1572,2000$.

[8] S. K. Calderwood, M. A. Khaleque, D. B. Sawyer, and D. R. Ciocca, "Heat shock proteins in cancer: chaperones of tumorigenesis," Trends in Biochemical Sciences, vol. 31, no. 3, pp. 164-172, 2006.

[9] C. Garrido, A. Fromentin, B. Bonnotte et al., "Heat shock protein 27 enhances the tumorigenicity of immunogenic rat colon carcinoma cell clones," Cancer Research, vol. 58, no. 23, pp. 5495-5499, 1998.

[10] S. Gurbuxani, J. M. Bruey, A. Fromentin et al., "Selective depletion of inducible HSP70 enhances immunogenicity of rat colon cancer cells," Oncogene, vol. 20, no. 51, pp. 7478-7485, 2001.

[11] C. De Simone, P. Ferranti, G. Picariello et al., "Peptides from water buffalo cheese whey induced senescence cell death via ceramide secretion in human colon adenocarcinoma cell line," Molecular Nutrition and Food Research, vol. 55, no. 2, pp. 229238, 2011.

[12] R. Hayashi, Y. Ishii, H. Ochiai et al., "Suppression of heat shock protein 27 expression promotes 5 -fluorouracil sensitivity in colon cancer cells in a xenograft model," Oncology Reports, vol. 28, no. 4, pp. 1269-1274, 2012.

[13] P. Mehlen, A. Mehlen, J. Godet, and A. P. Arrigo, "hsp27 as a switch between differentiation and apoptosis in murine embryonic stem cells," Journal of Biological Chemistry, vol. 272, no. 50, pp. 31657-31665, 1997.

[14] D. R. Ciocca, S. Oesterreich, G. C. Chamness, W. L. McGuire, and S. A. W. Fuqua, "Biological and clinical implications of heat shock protein 27000 (Hsp27): a review," Journal of the National Cancer Institute, vol. 85, no. 19, pp. 1558-1570, 1993.

[15] P. Stiuso, G. Giuberti, A. Lombardi et al., " $\gamma$-Glutamyl 16diaminopropane derivative of vasoactive intestinal peptide: a potent anti-oxidative agent for human epidermoid cancer cells," Amino Acids, vol. 39, no. 3, pp. 661-670, 2010.

[16] L. Vigh, B. Maresca, and J. L. Harwood, "Does the membrane's physical state control the expression of heat shock and other genes?" Trends in Biochemical Sciences, vol. 23, no. 10, pp. 369374, 1998.

[17] Z. Török, N. M. Tsvetkova, G. Balogh et al., "Heat shock protein coinducers with no effect on protein denaturation specifically modulate the membrane lipid phase," Proceedings of the National Academy of Sciences of the United States of America, vol. 100, no. 6, pp. 3131-3136, 2003.

[18] E. Nagy, Z. Balogi, I. Gombos et al., "Hyperfluidization-coupled membrane microdomain reorganization is linked to activation of the heat shock response in a murine melanoma cell line," Proceedings of the National Academy of Sciences of the United States of America, vol. 104, no. 19, pp. 7945-7950, 2007.

[19] A. Budillon, F. Bruzzese, E. Di Gennaro, and M. Caraglia, "Multiple-target drugs: Inhibitors of heat shock protein 90 and of histone deacetylase," Current Drug Targets, vol. 6, no. 3, pp. 337-351, 2005.

[20] G. Misso, G. Giuberti, A. Lombardi et al., "Pharmacological inhibition of HSP90 and ras activity as a new strategy in the treatment of HNSCC," Journal of Cellular Physiology, vol. 228, no. 1, pp. 130-141, 2013.

[21] M. Caraglia, M. Marra, A. Budillon et al., "Chemotherapy regimen GOLF induces apoptosis in colon cancer cells through multi-chaperone complex inactivation and increased Raf-1 ubiquitin-dependent degradation," Cancer Biology and Therapy, vol. 4, no. 10, pp. 1159-1167, 2005.

[22] G. Vitale, S. Zappavigna, M. Marra et al., "The PPAR-gamma agonist troglitazone antagonizes survival pathways induced by STAT-3 in recombinant interferon-gamma treated pancreatic cancer cells," Biotechnology Advances, vol. 30, no. 1, pp. 169-184, 2012.

[23] G. L. Johnson and R. Lapadat, "Mitogen-activated protein kinase pathways mediated by ERK, JNK, and p38 protein kinases," Science, vol. 298, no. 5600, pp. 1911-1912, 2002.

[24] M. G. Wilkinson and J. B. A. Millar, "Control of the eukaryotic cell cycle by MAP kinase signaling pathways," The FASEB Journal, vol. 14, no. 14, pp. 2147-2157, 2000.

[25] S.-F. Chen, S. Nieh, S.-W. Jao et al., "Quercetin suppresses drugresistant spheres via the p38 MAPK-Hsp27 apoptotic pathway in oral cancer cells," PLoS ONE, vol. 7, no. 11, Article ID e49275, 2012.

[26] I. Gomez-Monterrey, P. Campiglia, A. Bertamino et al., "A novel quinone-based derivative (DTNQ-Pro) induces apoptotic death via modulation/reduction of hsp expression in a human colon adenocarcinoma cell line," British Journal of Pharmacology, vol. 160, no. 4, pp. 931-940, 2010.

[27] C. De Simone, G. Picariello, G. Mamone et al., "Characterisation and cytomodulatory properties of peptides from Mozzarella di Bufala Campana cheese whey," Journal of Peptide Science, vol. 15, no. 3, pp. 251-258, 2009.

[28] F. Herz, A. Schermer, M. Halwer, and L. H. Bogart, "Alkaline phosphatase in HT-29, a human colon cancer cell line: Influence of sodium butyrate and hyperosmolality," Archives of Biochemistry and Biophysics, vol. 210, no. 2, pp. 581-591, 1981.

[29] M. M. Bradford, "A rapid and sensitive method for the quantitation of microgram quantities of protein utilizing the principle of protein dye binding," Analytical Biochemistry, vol. 72, no. 1-2, pp. 248-254, 1976.

[30] Q. M. Ding, T. C. Ko, and B. Mark Evers, "Caco-2 intestinal cell differentiation is associated with G1 arrest and suppression of CDK2 and CDK4," American Journal of Physiology, vol. 275, no. 5, pp. C1193-C1200, 1998.

[31] H. Matsumoto, R. H. Erickson, J. R. Gum, M. Yoshioka, E. Gum, and Y. S. Kim, "Biosynthesis of alkaline phosphatase during differentiation of the human colon cancer cell line Caco-2," Gastroenterology, vol. 98, no. 5 I, pp. 1199-1207, 1990.

[32] D. A. Wink and J. B. Mitchell, "Chemical biology of nitric oxide: Insights into regulatory, cytotoxic, and cytoprotective mechanisms of nitric oxide," Free Radical Biology and Medicine, vol. 25, no. 4-5, pp. 434-456, 1998.

[33] H. Huang and D. J. Tindall, "Dynamic FoxO transcription factors," Journal of Cell Science, vol. 120, no. 15, pp. 2479-2487, 2007. 
[34] S. Popat, A. Matakidou, and R. S. Houlston, "Thymidylatesynthase expression and prognosis in colorectal cancer: a systematic review and meta-analysis," Journal of Clinical Oncology, vol. 22, no. 3, pp. 529-536, 2004.

[35] L. Whitesell and S. L. Lindquist, "HSP90 and the chaperoning of cancer," Nature Reviews Cancer, vol. 5, no. 10, pp. 761-772, 2005. 

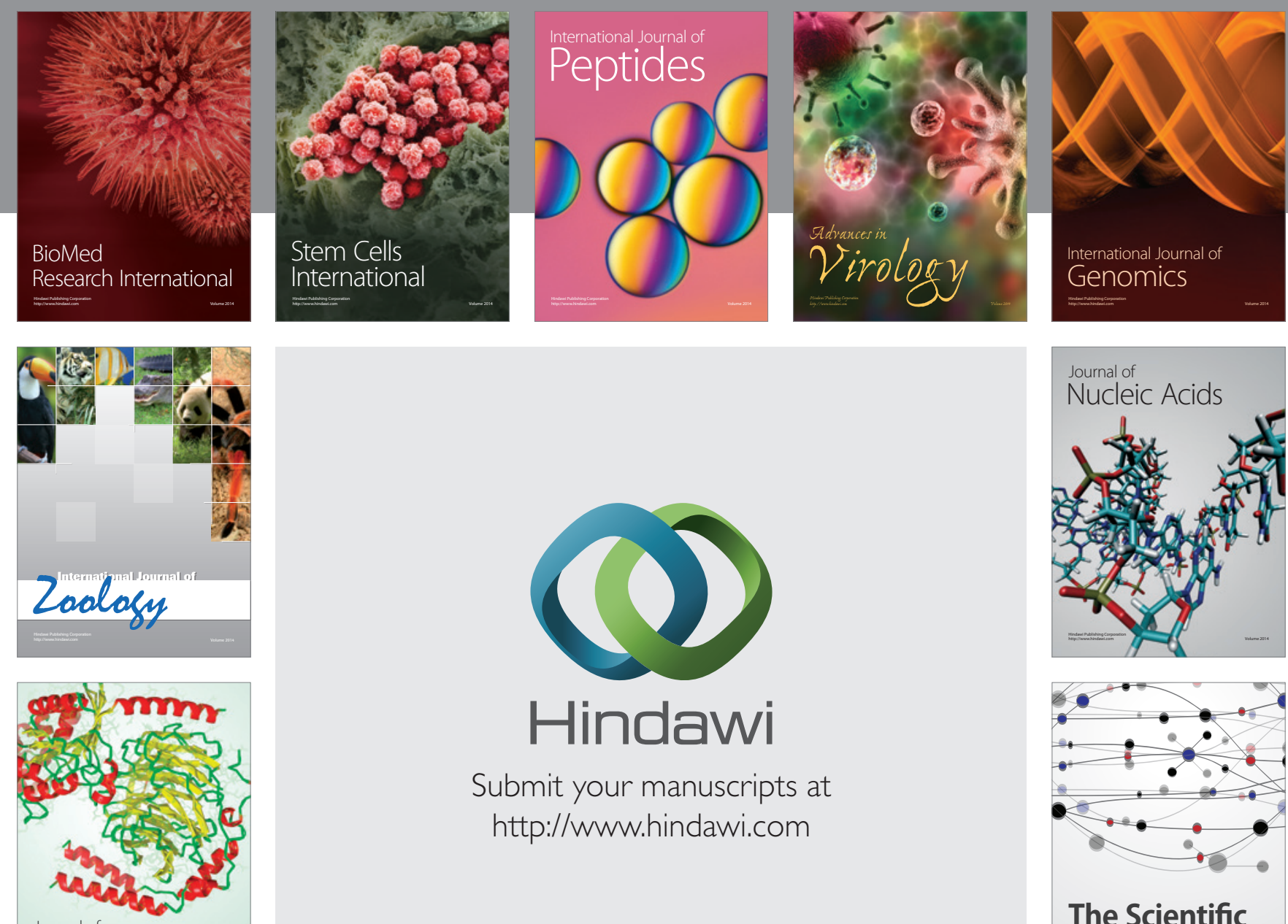

Submit your manuscripts at

http://www.hindawi.com

Journal of
Signal Transduction
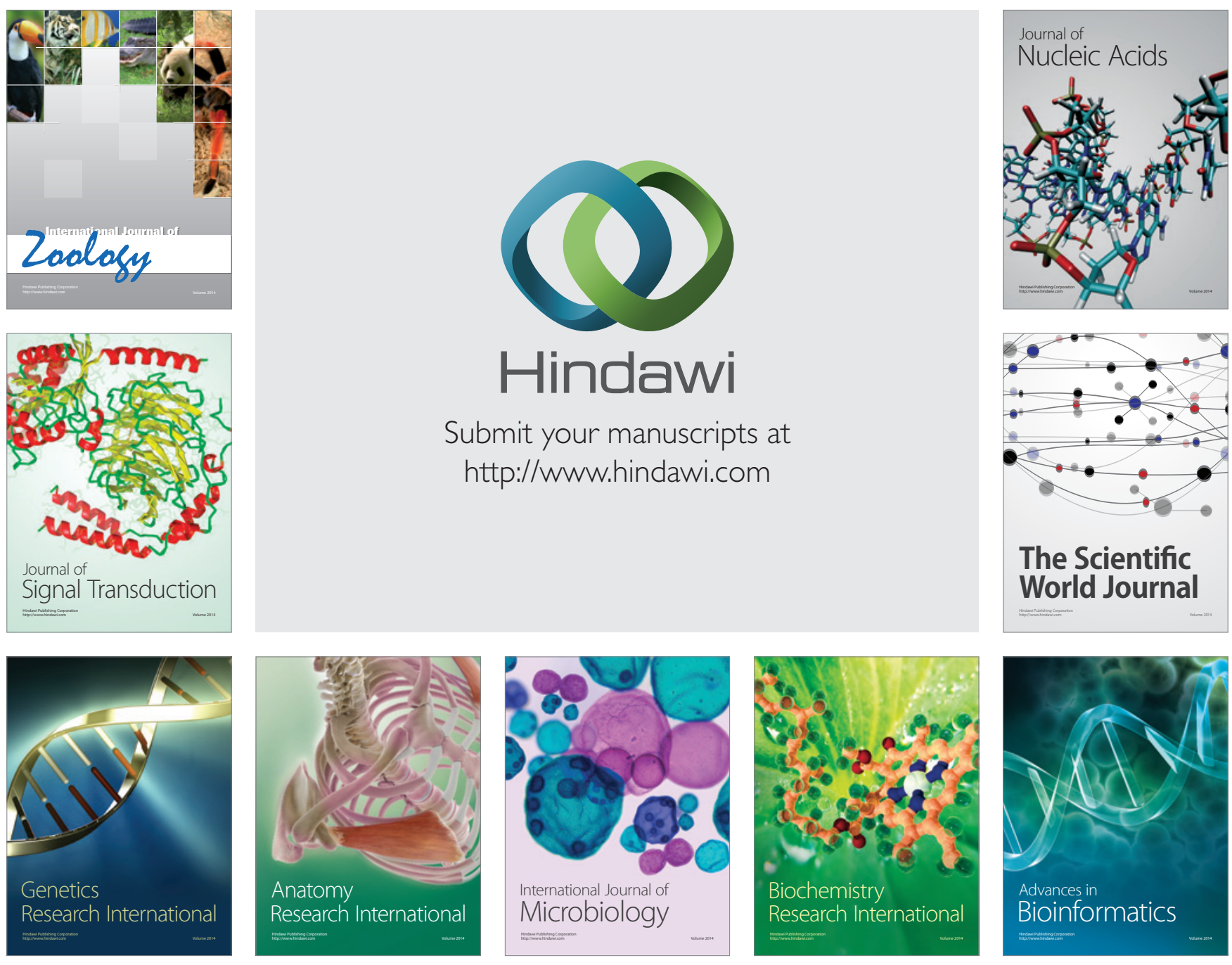

The Scientific World Journal
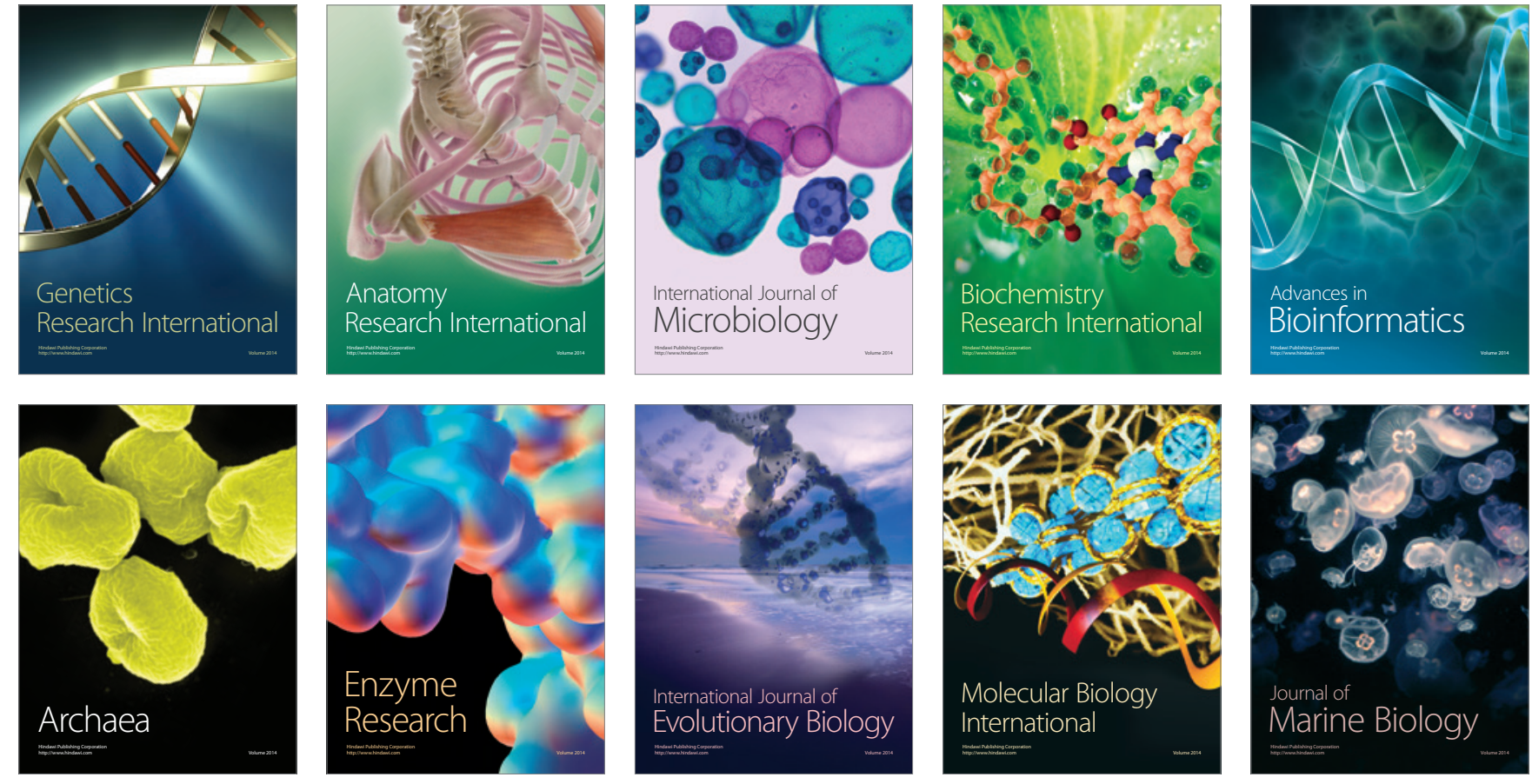